\section{UTILIZING GOOGLE MY MAPS IN THE CLASSROOM}

\author{
William S. Duffy
}

\section{ABOUT THE AUTHORS}

William S. Duffy is Faculty Fellow for Faculty Development at St. Philip's College. He received his Ph.D. in Classics from the University at Buffalo. He discovered Google My Maps as a teaching tool for his Ancient Travel and Ethnography Class and has since used it in several other courses.

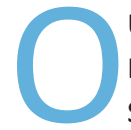

ur students are entering a world where they must both engage with maps and map-based software on a daily basis and communicate effectively through digital tools and media. Incorporating projects that allow students to build skills along these lines therefore has the potential to provide them with significant benefits. To that end, in Spring 2013, I introduced a Google My Maps project-" The Roadrunners' Guide to the Ancient World" (2019)into my Ancient Travel and Ethnography class. The Roadrunners' Guide was an interactive map with color-coded markers on a custom Google My Maps leading to travel-guide style descriptions of ancient cities, built by students in WordPress. This project led to increased student engagement, original and detailed projects, and a marked increase in student ownership of and pride in their work, which Conley and French (2013) among others see as key factors in student success. This experience, repeated in different courses and semesters, convinced me that Google My Maps provides teachers a versatile, valuable tool to help students build course specific knowledge and universally valuable skills with digital tools which, as Pfannenstiel (2010) notes, even modern students often struggle to use in academic and professional settings.

\section{Value to Students}

Integrating Google My Maps into the classroom can develop students' ability to utilize maps and special technologies. These skills are becoming increasingly vital to classroom and life success in all fields (Bednarz, Acheson, \& Bednarz, 2006). However, only $20 \%$ of $12^{\text {th }}$ graders scored at or above a proficient level in geography on the 2010 National Assessment of Educational Progress exam (the latest exam to measure these students in this field), the largest representative national assessment of student academic capacity (National Assessment of Educational Progress, 2010), lower than in the two previous examinations. This is the second lowest level of proficiency of all subjects tested, indicating that students have a significant deficiency in geographic knowledge that almost certainly follows them to college. Google My Maps-based activities therefore allow students to gain what they both lack and need.

Google My Maps-based projects also allow students to have what Lombardi (2007) describes as authentic learning experiences - using a software tool and digital skills they will use in their real and professional lives to create a resource that will be used outside the classroom. Education research suggests that students engaged in authentic learning have higher levels of perseverance, satisfaction, and success (Lombardi, 2007). In the context of authentic learning, Google My Maps' ability to allow users to change who can access or contribute to a given map at will provides an additional element of safety. Since teachers can choose when and how students can contribute to a given map project, and when and to what degree the final project will be made available to the public, they can ensure that student work is only presented to broader audiences when it is ready for the public. Students also have the ability to continue to improve (or remove) their work after the completion of their project, and share it with potentially interested parties. For example, in Spring 2013, two of my students presented their projects at national conferences, and one used his to win a post-graduation job.

\section{Designing Google My Maps Projects: Guidelines}

Google My Maps is a free and versatile tool that enables the creation of engaging class projects that help students learn skills that are vital in the modern age. However, as with all tools, faculty members should take care when designing a project around

\section{Google My Maps provides teachers} with a free and comparatively simple way to help students build their knowledge in geography, integrating with geographic software and digital publication while engaging deeply with course materials. 
the software. First, teachers should design a project that benefits from Google My Maps' geographic information and interactive interface. For example, while a heat map of access to health and child care might well be an excellent use of the Google My Maps interface, an analysis of universal best practices in childcare probably would not be. Second, teachers should give students (and themselves) access to an online Google My Maps tutorial and ample time to practice using it; teachers must not assume that students already have command over Google My Maps or any digital tool (Watson \& Pecchioni, 2011). Finally, teachers should take care when assessing student contributions to public maps, with a particular focus on plagiarism and acceptable discourse. If an individual student project is beneath the standards of the school, the teacher may have to request that the student redo the project before the class's creation is made public, or in extreme cases prevent public access to unacceptable student contributions. However, in my experience, such problems are extremely rare.

\section{Google My Maps Functions}

Google My Maps has four basic tools, each of which can be adapted for pedagogical purposes, either individually or in concert: layers, polygons, markers, and measurements. I have largely limited myself to markers in my student projects, although I plan to utilize more tools in the future. Below is a brief description of each tool and some of its potential educational functions:

- Layers create different maps that can be viewed or edited together or in isolation. This is useful for differentiating between different students work or if there is pedagogical value from overlaying different sets of geographic information (i.e. the borders of nations and empires in different eras).

- Polygons allow for the creation of shapes on the map. Once the polygon is completed, Google My Maps allows for the coloration and shading of the polygon and provides a marker in which one may include information or a link to outside media. This can be used to create heat maps and infographics that illustrate a wide variety of geographic and cultural information, such as the prevalence of food deserts in a given community.

- Markers place an icon on the map. Google provides a number of variant icons that can be used to signal information, and each icon has a space for providing additional information or links to outside resources. This is the most versatile Google My Maps tool for educational purposes. A Google My Maps resource can use the shapes and colors of the markers to provide information and/or organize the entries, and the entry space allows students to add written material, images, or external links to the resource. The information provided in these markers, and the markers Google My Maps automatically creates when a polygon or line is made, provides the easiest space for students to showcase their skills and course knowledge.

- The Measurement tool allows for the measuring of distance between points on the map. However, not all information accessed this way stays permanently on the site, so they may function better as parts of student assignments than as an element of a final, public Google My Maps project.

\section{Conclusion}

Google My Maps provides teachers with a free and comparatively simple way to help students build their knowledge in geography, integrating with geographic software and digital publication while engaging deeply with course materials. While adapting the tool to your course will take time and creativity, the potential rewards are more than worth the effort.

\section{References}

Bednarz, S. W., Acheson, G., \& Bednarz, R. S. (2006). Maps and map learning in social studies. Social Education, 70(7), 398-404.

Conley, D. T., \& French, E. M. (2013). Student ownership of learning as a key component of college readiness. American Behavioral Scientist, 58(8), 1018-1034.

Lombardi, M. M. (2007). Authentic learning for the 21st century: An overview (ELI Paper 1: 2007). Retrieved from Educause website: https://library.educause.edu/-/media/files/ library/2007/1/eli3009-pdf.pdf

Pfannenstiel, A. N. (2010). Digital literacies and academic integrity. International Journal for Educational Integrity, 6(2), 41-49.

National Assessment of Educational Progress (2010). The nation's report card: Geography grade 12 national results. Retrieved from https://www.nationsreportcard.gov/ geography_2010/g12_nat.aspx

The roadrunners' guide to the ancient world. (2019, May 29). Retrieved from roadrunnersguidetotheancientworld.com/

Watson, J. A., \& Pecchioni, L. L. (2011). Digital natives and digital media in the college classroom: Assignment design and impacts on student learning. Educational Media International, 48(4), 307-320. 